Article

\title{
Esterification of Palm Fatty Acid Distillate for Biodiesel Production Catalyzed by Synthesized Kenaf Seed Cake-Based Sulfonated Catalyst
}

\author{
Shehu-Ibrahim Akinfalabi ${ }^{1}\left(\mathbb{D}\right.$, Umer Rashid ${ }^{1, * \mathbb{C}}$, Thomas Yaw Choong Shean ${ }^{2}$, \\ Imededdine Arbi Nehdi ${ }^{3,4}$, Hassen Mohamed Sbihi ${ }^{3}$ and Mohamed Mossad Gewik ${ }^{3}$ \\ 1 Institute of Advanced Technology, Universiti Putra Malaysia, Serdang 43400 UPM, Selangor, Malaysia; \\ akinfalabs@gmail.com \\ 2 Department of Chemical and Environmental Engineering, Engineering Faculty, Universiti Putra Malaysia, \\ Serdang 43400 UPM, Selangor, Malaysia; csthomas@upm.edu.my \\ 3 Chemistry Department, College of Science, King Saud University, Riyadh 1145, Saudi Arabia; \\ inahdi@ksu.edu.sa (I.A.N.); hmsbihi@ksu.edu.sa (H.M.S.); mmossad@ksu.edu.sa (M.M.G.) \\ 4 Laboratoire de Recherche LR18ES08, Chemistry Department, Science College, Tunis El Manar University, \\ Tunis 2092, Tunisia \\ * Correspondence: umer.rashid@upm.edu.my; Tel.: +60-3-97697393
}

Received: 13 March 2019; Accepted: 16 April 2019; Published: 24 May 2019

\begin{abstract}
Sulfonated kenaf seed cake ( $\left.\mathrm{SO}_{3} \mathrm{H}-\mathrm{KSC}\right)$ catalyst, was synthesized to aid biodiesel production from palm fatty acid distillate (PFAD). It was chemically activated with phosphoric acid for an impregnation period of $24 \mathrm{~h}$ in order to enhance the porosity and the specific surface area of kenaf seed cake (KSC). After the carbonization and sulfonation, the resultant catalyst was characterized with powder X-ray diffraction (XRD), Brunauer-Emmett-Teller (BET), Fourier transform infrared (FTIR) spectroscopy, field emission scanning electron microscope (FESEM), $\mathrm{NH}_{3}$-temperature programmed desorption ( $\mathrm{NH}_{3}$-TPD) and thermogravimetric analysis (TGA). The $\mathrm{SO}_{3} \mathrm{H}-\mathrm{KSC}$ catalyst was amorphous in nature and had an acid density of $14.32 \mathrm{mmol} / \mathrm{g}$, specific surface area of $365.63 \mathrm{~m}^{2} / \mathrm{g}$, pore volume of $0.31 \mathrm{~cm}^{3} / \mathrm{g}$ and pore diameter of $2.89 \mathrm{~nm}$. At optimum esterification conditions-reaction time 90 mins, temperature of $338 \mathrm{~K}$, methanol:PFAD molar ratio of 10:1 and catalyst concentration of $2 \mathrm{wt} . \%$ - a free fatty acid (FFA) conversion of $98.7 \%$ and fatty acid methyl esters (FAME) yield of $97.9 \%$ was achieved. The synthesized $\mathrm{SO}_{3} \mathrm{H}-\mathrm{KSC}$ catalyst underwent five reaction cycles while maintaining a fatty acid methyl esters (FAME) yield and free fatty acid (FFA) conversion of $>90 \%$. Thus, the $\mathrm{SO}_{3} \mathrm{H}-\mathrm{KSC}$ catalyst was shown to be an excellent application of bio-based material as a precursor for catalyst synthesis for esterification of PFAD.
\end{abstract}

Keywords: kenaf seed cake; sulfonation; esterification; FFA conversion; reusability

\section{Introduction}

Catalyst synthesis has become an interesting area of research in the production of biodiesel in recent times. Homogeneous catalysts such as $\mathrm{NaOH}, \mathrm{KOH}$ and $\mathrm{H}_{2} \mathrm{SO}_{4}$ were more prevalent in conventional biodiesel production due to their high conversion rate and reduced reaction time [1]. Homogeneous catalysts however, had some drawbacks-such as corrosion of reactors, increased solvent usage, non-recyclability of the catalysts, multiple purification steps of the produced biodiesel, generation of waste water [2] and being environmentally unfriendly-which affect the total cost of biodiesel production [3]. On the other hand, different heterogeneous catalysts [4] such as zirconia [5], eggshells [6], ferric alginate [7], titanium dioxide [8], silica nanoparticles [9], and even catalytic technologies [10], were then exploited as available alternatives to homogeneous catalysts for the 
production of biodiesel. However, these streams of heterogeneous catalysts require expensive materials, have complicated synthesis routes and record low catalytic activity, whereas catalysts derived from biomass (bio-based catalysts), have an easy synthesis route, are readily abundant and are environmentally benign. Hence, bio-based catalysts emerged as the leading alternatives owing to their immense advantages, thereby reducing the total cost of biodiesel production, while also reducing the global environmental threat and increasing their feasibility for industrial usage [3].

Among the abundant streams of biomass sources is kenaf seed (Hibiscus cannabinus, L). Economically, kenaf seed is generally regarded as a crop that can easily replace tobacco, because it is well adapted to arid regions, and is seen as Malaysia's next industrial crop because of its industrial potential. It is currently grown in Asia (Malaysia, India, Thailand and China) [11]. Kenaf seed was discovered in the early 1970s and later publicized in the 1990s as an early replacement, and a potential starting material, for textiles and fiber board, and as a fuel source [12]. Kenaf seed is an herbaceous annual plant that belongs to the family of Malvaceae. Two kinds of fiber exist that may serve as a potential source for activated carbon (AC) which, when further chemically activated, can serve as a bio-based catalyst. As a result, the synthesis of sulfonated bio-based catalysts from kenaf seed has become important for the production of biodiesel from acidic oils with high free fatty acid (FFA). Some bio-based catalysts that have been previously synthesized for the production of biodiesel are: palm seed cake [13], eggshells [6], sugarcane bagasse [14] and rice husk-derived sodium silicate [15].

In biodiesel production, two major components are vital, the catalyst (precursor) and the fatty acid source (feedstock). Having identified our catalyst source (kenaf seed cake), it is important to identify our fatty acid source. Palm fatty acid distillate (PFAD), is a common residue in the oil palm industry and is utilized as a feedstock in the esterification reaction to produce biodiesel. Globally, Malaysia ranks second in palm oil production, behind only Indonesia. In 2017 alone, Malaysia produced 21,000 MT of palm oil, which accounted for $32 \%$ of the global production of palm oil [16]. Hence, the abundant production of PFAD in Malaysia is imminent. PFAD consists of about $90 \%$ FFA and $10 \%$ triglycerides, diglycerides, monoglycerides and small amounts of other impurities [17].

In previous works on biodiesel synthesis where palm seed cake-derived bio-based catalysts were utilized for the esterification of PFAD, FAME yield of $97.8 \%$ and FFA conversion of $98.2 \%$ were achieved at the following optimum conditions: methanol-PFAD ratio of 9:1; esterification time and temperature of $2 \mathrm{~h}$ and $60{ }^{\circ} \mathrm{C}$, respectively; and finally, a catalyst concentration of $2.5 \mathrm{wt} . \%$ [13]. Similarly, oil transesterification at the optimum conditions of $2.5 \mathrm{wt} . \%$ catalyst concentration, 12:1 methanol:oil ratio, and a reaction temperature of $65^{\circ} \mathrm{C}$ for $30 \mathrm{~min}$ reaction time, yielded $97 \%$ FAME while using a rice husk-derived sodium silicate catalyst [18]. Sugar cane bagasse has also been used as a bio-based solid catalyst for the synthesis of methyl esters from PFAD. A FAME content of $80 \%$ was achieved with $11.5 \mathrm{wt} . \%$ of the catalyst weight and 20:1 methanol: PFAD weight ratio in $30 \mathrm{~min}$ reaction time [14]. In spite of the extensive previous work on bio-based catalysts, to the best of our knowledge, no work has been done on the synthesis of kenaf seed cake as a catalyst for biodiesel production while using PFAD as feedstock.

Therefore, the main objective of this study was to address the synthesis and biodiesel performance of a kenaf seed cake (KSC)-derived catalyst while using PFAD as a fatty acid source, in order to introduce a new and improved bio-based catalyst into the realm of catalysis for the esterification reaction. Hence, we carried out a comprehensive characterization of the synthesized catalyst and optimization of the produced biodiesel. To analyze the synthesized catalyst's amorphous nature, X-ray diffraction (XRD) analysis was carried out. Thermo-gravimetric analysis (TGA) was done to check the thermal strength of the catalyst while Fourier transform infrared (FT-IR) analysis confirmed the presence of the sulfonic group attachment to the activated carbon (AC) of the KSC. The Brunauer-Emmett-Teller (BET) analysis was used to assess the surface area, pore size and pore diameter. $\mathrm{NH}_{3}$-temperature programmed desorption ( $\mathrm{NH}_{3}$-TPD) confirmed the active acid site distribution of the KSC and the morphology of the catalyst was illustrated by a field emission scanning electron microscope (FESEM). The reusability potential was confirmed by the carbon hydrogen nitrogen sulfur (CHNS) analysis. 
Reaction optimization variables such as the reaction time and temperature, catalyst concentration and methanol: PFAD molar ratio were studied in detail for a higher yield and conversion. The fuel properties of the FAME were also analyzed based on its reusability potential.

\section{Results and Discussion}

\subsection{Surface Area Enhancements via Initial Chemical Activation}

The surface area of the sulfonated kenaf seed cake $\left(\mathrm{SO}_{3} \mathrm{H}-\mathrm{KSC}\right)$ was greatly enhanced compared to the initial starting material, as observed from the Brunauer-Emmett-Teller (BET) surface area analysis. The improvement of pore size and surface area, as a result of the dehydration process of chemical activating agents, from the kenaf seed cake (KSC), to the activated carbon kenaf seed cake (AC-KSC) and the final sulfonated-kenaf seed cake $\left(\mathrm{SO}_{3} \mathrm{H}-\mathrm{KSC}\right)$, is an indication that $\mathrm{H}_{3} \mathrm{PO}_{4}$ when used for chemical activation, can aid in surface area and pore development. These materials were all analyzed in nitrogen desorption/adsorption measurements and are summarized in Table 1 below. The adsorption isotherms showed that AC-KSC has better material surface properties, with respect to its surface area and pore diameter and pore size than those of KSC. Also, it is observed that AC-KSC has slightly better surface properties than those of $\mathrm{SO}_{3} \mathrm{H}-\mathrm{KSC}$. This is due to the sulfonation process; upon sulfonation, the pores and surface area will slightly shrink as a result of the attachment of the functional group to its surface. Hence, this provides justification for the initial pretreatment with phosphoric acid $\left(\mathrm{H}_{3} \mathrm{PO}_{4}\right)$ to make room for an improved surface area and pore volume [19].

Table 1. BET analysis of kenaf seed cake (KSC), activated carbon (AC)-KSC and sulfonated-kenaf seed cake $\left(\mathrm{SO}_{3} \mathrm{H}-\mathrm{KSC}\right)$.

\begin{tabular}{cccc}
\hline Sample & Specific Surface Area $\left(\mathbf{m}^{2} / \mathbf{g}\right)$ & Pore Volume $\left(\mathrm{cm}^{3} / \mathbf{g}\right)$ & Pore Diameter $(\mathbf{n m})$ \\
\hline $\mathrm{KSC}$ & 23.01 & 0.02 & 0.93 \\
$\mathrm{AC}-\mathrm{KSC}$ & 375.18 & 0.39 & 3.07 \\
$\mathrm{SO}_{3} \mathrm{H}-\mathrm{KSC}$ & 365.63 & 0.31 & 2.89 \\
\hline
\end{tabular}

\subsection{Catalyst Characterization}

\subsubsection{Phase Identification}

The amorphous phase identification of the $\mathrm{SO}_{3} \mathrm{H}-\mathrm{KSC}$, is shown in Figure 1. The X-ray diffraction (XRD) pattern shows a broad, although weak, peak located between 20 and $282 \theta$ (degree) angle for $\mathrm{SO}_{3} \mathrm{H}-\mathrm{KSC}$, AC-KSC and KSC. These broad weak peaks of (002) at $2 \theta$ angles, and in the absence of sharp peaks, indicate that the synthesized catalyst is predominantly amorphous in nature. Although another broad weak peak is seen at 46 to 49 (101) for the KSC, this is also generally attributable to bio-based carbon materials [20]. The tiny peak seen on $\mathrm{SO}_{3} \mathrm{H}-\mathrm{KSC}$ may be as a result of noise in the kenaf seed cake during the chemical activation and sulfonation process. This amorphous nature confirms that the carbon sheets are arranged in a relatively random manner and are carbonaceous in nature. This, therefore, shows that the synthesized catalysts are amorphous bio-based catalysts after undergoing both thermal and chemical treatments. Similar diffraction peaks have been reported elsewhere [21]. 


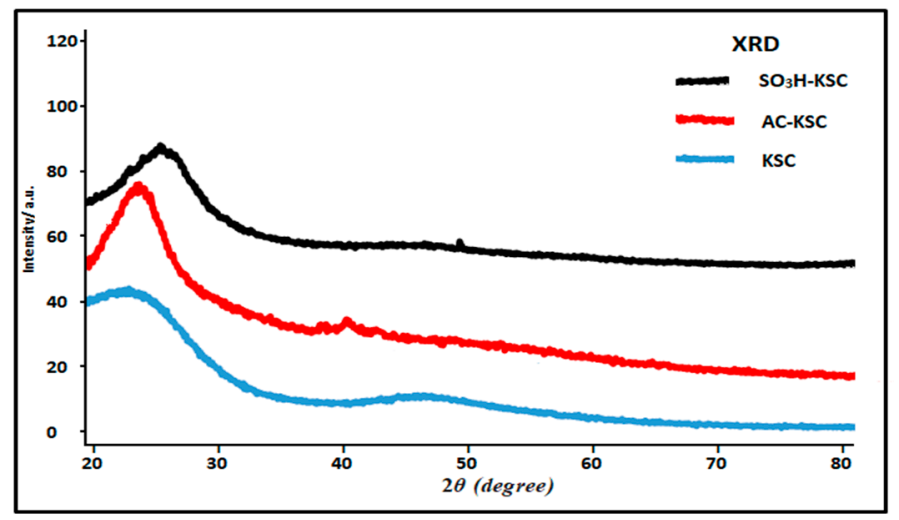

Figure 1. XRD patterns of $\mathrm{KSC}, \mathrm{AC}-\mathrm{KSC}$ and $\mathrm{SO}_{3} \mathrm{H}-\mathrm{KSC}$ catalysts.

2.2.2. Morphology

The field emission scanning electron microscope (FESEM) micrographs of the KSC, AC-KSC and $\mathrm{SO}_{3} \mathrm{H}-\mathrm{KSC}$ catalysts are shown in Figure 2 below.

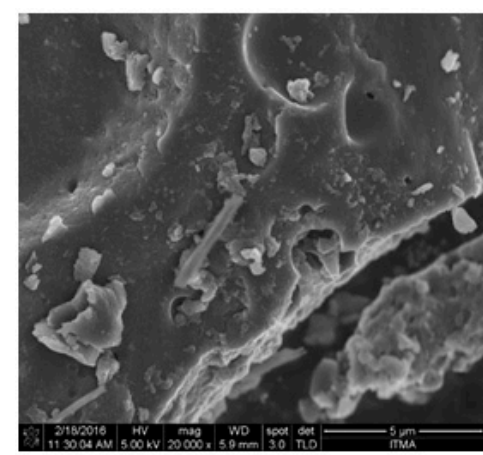

KSC

(a)

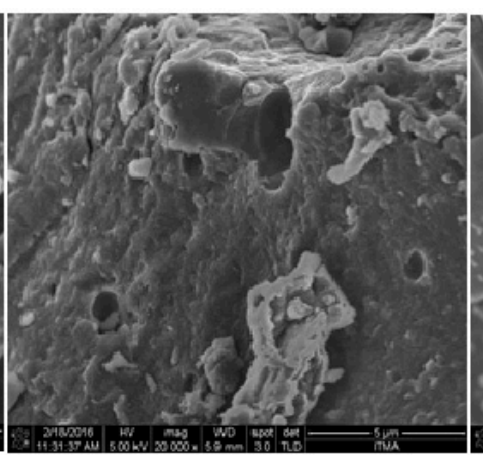

AC-KSC

(b)

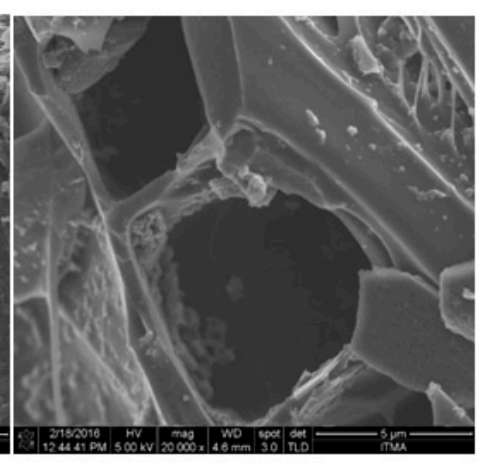

$\mathrm{SO}_{3} \mathrm{H}-\mathrm{KSC}$

(c)

Figure 2. FESEM micrographs of $\mathrm{KSC}(\mathbf{a}), \mathrm{AC}-\mathrm{KSC}(\mathbf{b})$ and $\mathrm{SO}_{3} \mathrm{H}-\mathrm{KSC}$ (c) catalysts.

The $\mathrm{SO}_{3} \mathrm{H}-\mathrm{KSC}$ has a clear pore enhancement as compared to the KSC which did not undergo any treatment. The surface structure of the $\mathrm{SO}_{3} \mathrm{H}-\mathrm{KSC}$ is seen to have significantly improved due to the pretreatment of the chemical activation by the soaking in phosphoric acid and sulfonation. Besides the fact that the materials exhibited irregular and aggregate particles, the pores were evident in $\mathrm{SO}_{3} \mathrm{H}-\mathrm{KSC}$ when viewed at $5 \mu \mathrm{m}$. At the same magnifying scale, the pores in KSC were insignificant. Also, it can be observed that the pores in AC-KSC were evident and aggregated but not as pronounced as those of the $\mathrm{SO}_{3} \mathrm{H}-\mathrm{KSC}$. Hence, the phosphoric acid successfully improved the porosity of the $\mathrm{SO}_{3} \mathrm{H}-\mathrm{KSC}$ catalyst.

The elemental analysis also highlighted the presence of all the abundant elements in our sample. As expected, and observed in Table 2, carbon is more prevalent than oxygen, sulfur and phosphorus. The small amount of sulfur and phosphorus for $\mathrm{SO}_{3} \mathrm{H}-\mathrm{KSC}$ confirms the sulfonation. The sulfur also confirms the functionalization phase using sulfur, while phosphorus is used for the chemical impregnation phase. 
Table 2. Elemental and acid site density analysis of $\mathrm{KSC}, \mathrm{AC}-\mathrm{KSC}$ and $\mathrm{SO}_{3} \mathrm{H}-\mathrm{KSC}$ catalysts.

\begin{tabular}{|c|c|c|c|c|c|c|c|c|c|}
\hline \multirow{2}{*}{ Sample } & \multicolumn{2}{|c|}{$\mathrm{C}$} & \multicolumn{2}{|c|}{ O } & \multicolumn{2}{|c|}{$\mathbf{P}$} & \multicolumn{2}{|c|}{$S$} & \multirow{2}{*}{$\begin{array}{c}\text { Total } \\
\text { Acidity } \\
\left(\mathrm{mmol} \mathrm{g}^{-1}\right)\end{array}$} \\
\hline & $\begin{array}{c}{ }^{a} \text { Weight } \\
(\%)\end{array}$ & b Atomicity & $\begin{array}{c}{ }^{a} \text { Weight } \\
(\%)\end{array}$ & b Atomicity & $\begin{array}{c}{ }^{\text {a }} \text { Weight } \\
(\%)\end{array}$ & b Atomicity & $\begin{array}{c}{ }^{a} \text { Weight } \\
(\%)\end{array}$ & b Atomicity & \\
\hline AC-KSC & 84.91 & 87.14 & 10.51 & 10.66 & 4.37 & 2.10 & 0.21 & 0.1 & 8.37 \\
\hline $\mathrm{SO}_{3} \mathrm{H}-\mathrm{KSC}$ & 60.65 & 78.53 & 29.17 & 16.14 & 4.84 & 1.42 & 5.34 & 3.91 & 14.32 \\
\hline
\end{tabular}

${ }^{a}$ Measured using EDS analysis; ${ }^{b}$ Measured using CHNS elemental analysis.

\subsubsection{Acid Density}

The acid distribution and density of the $\mathrm{SO}_{3} \mathrm{H}-\mathrm{KSC}$ catalyst was analyzed with ammoniatemperature programmed desorption $\left(\mathrm{NH}_{3}-\mathrm{TPD}\right)$. Figure 3 shows the ammonia desorption peaks of the KSC, AC-KSC and $\mathrm{SO}_{3} \mathrm{H}-\mathrm{KSC}$. Tables 1 and 2 highlight the elemental composition, total acid sites, pore diameter and specific surface area of all the stages of the catalyst preparation. The $\mathrm{SO}_{3} \mathrm{H}-\mathrm{KSC}$ showed two strong ammonia desorption peaks, one at $786 \mathrm{~K}$ and the other at Tmax $1015 \mathrm{~K}$. These temperatures, corresponding to the peaks, are indicators of strong acid sites and density, and show that the synthesized catalyst has the acidic requirement for effective protonation. The AC-KSC on the other hand has one peak, whose corresponding temperature (526 K) signifies a weak acid site [22]. The KSC shows an insignificant ammonia desorption peak, recorded from $453 \mathrm{~K}$ to $483 \mathrm{~K}$ but which lacks the intensity and acid density needed to be fit for protonation [23]. Moreover, this peak could be as a result of the interaction between the $-\mathrm{NH}_{3}$ with incompletely formed carbon sheets and the $-\mathrm{SO}_{3} \mathrm{H}$ functional group [24]. Furthermore, the total acidity of KSC, AC-KSC and $\mathrm{SO}_{3} \mathrm{H}-\mathrm{KSC}$ are in the order of $0.13 \mathrm{mmol} / \mathrm{g}, 8.37 \mathrm{mmol} / \mathrm{g}$ and $14.32 \mathrm{mmol} / \mathrm{g}$, respectively, as presented in Table 2 . This shows that the $\mathrm{SO}_{3} \mathrm{H}-\mathrm{KSC}$ has better catalytic properties with regards to its acidity as a result of the catalyst synthetic route. Similar desorption peaks and total acidity have been reported elsewhere by Dawodu et al. (2014) [25].

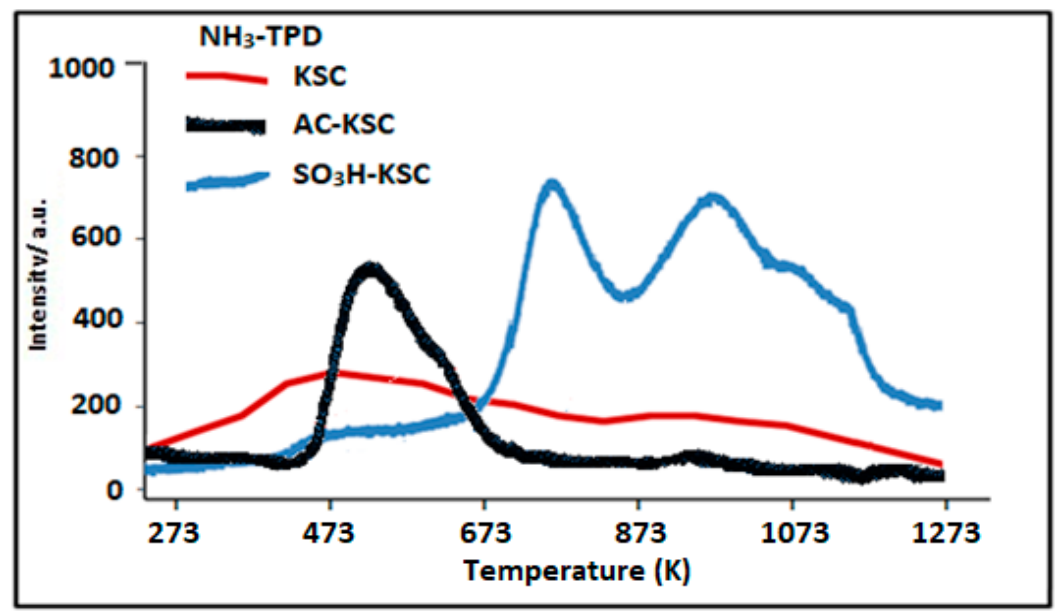

Figure 3. $\mathrm{NH}_{3}$-TPD of $\mathrm{KSC}, \mathrm{AC}-\mathrm{KSC}$ and $\mathrm{SO}_{3} \mathrm{H}-\mathrm{KSC}$ catalysts.

\subsubsection{FT-IR Analysis}

Figure 4 shows the IR spectra of the unsulfonated $\mathrm{KSC}, \mathrm{AC}-\mathrm{KSC}$ and $\mathrm{SO}_{3} \mathrm{H}-\mathrm{KSC}$ catalysts. A typical absorption signal recorded at $1092 \mathrm{~cm}^{-1}$ for the $\mathrm{SO}_{3} \mathrm{H}-\mathrm{KSC}$ confirms the attachment of a sulfonic group $\left(-\mathrm{SO}_{3} \mathrm{H}\right)$, whereas this band is not observed in the AC-KSC and KSC. The $\mathrm{SO}_{3} \mathrm{H}-\mathrm{KSC}$ exhibited another band of sulfur species recorded at $1210-1250 \mathrm{~cm}^{-1}$, belonging to the functional group $\mathrm{O}=\mathrm{S}=\mathrm{O}$, which is also as a result of the sulfonation process. The appearance of these bands after sulfonation strongly supports the sulfonating technique of bio-based materials adopted for this study [26]. The stretching band observed at $1518 \mathrm{~cm}^{-1}(\mathrm{C}=\mathrm{O})$ indicates the presence of carbonyl functional groups for both the $\mathrm{KSC}$ and $\mathrm{SO}_{3} \mathrm{H}-\mathrm{KSC}$ catalysts, which is characteristically designated for incompletely pyrolyzed 
carbons [27]. The presence of other stretching bands recorded at $3410 \mathrm{~cm}^{-1}$ is a depiction of the $-\mathrm{OH}$ group, while the band at $1290 \mathrm{~cm}^{-1}$ recorded for both AC-KSC and $\mathrm{SO}_{3} \mathrm{H}-\mathrm{KSC}$ indicates the presence of $\mathrm{P}=\mathrm{O}$, which may suggest that the chemical activation of $\mathrm{H}_{3} \mathrm{PO}_{4}$ on the $\mathrm{KSC}$ has been duly incorporated [21].

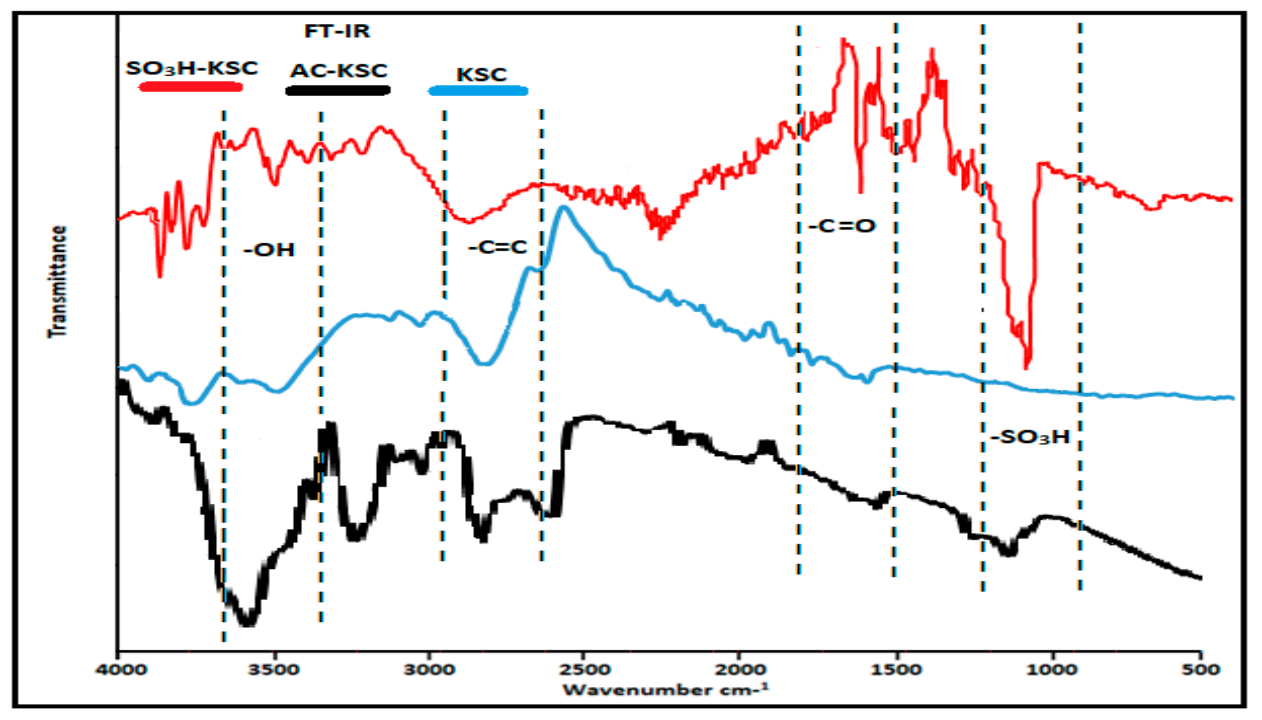

Figure 4. FT-IR spectra of $\mathrm{KSC}, \mathrm{AC}-\mathrm{KSC}$ and $\mathrm{SO}_{3} \mathrm{H}-\mathrm{KSC}$ catalysts.

\subsubsection{Thermal Stability}

We investigated the thermal strength of the $\mathrm{KSC}, \mathrm{AC}-\mathrm{KSC}$ and synthesized $\mathrm{SO}_{3} \mathrm{H}-\mathrm{KSC}$ catalysts as shown in Figure 5.
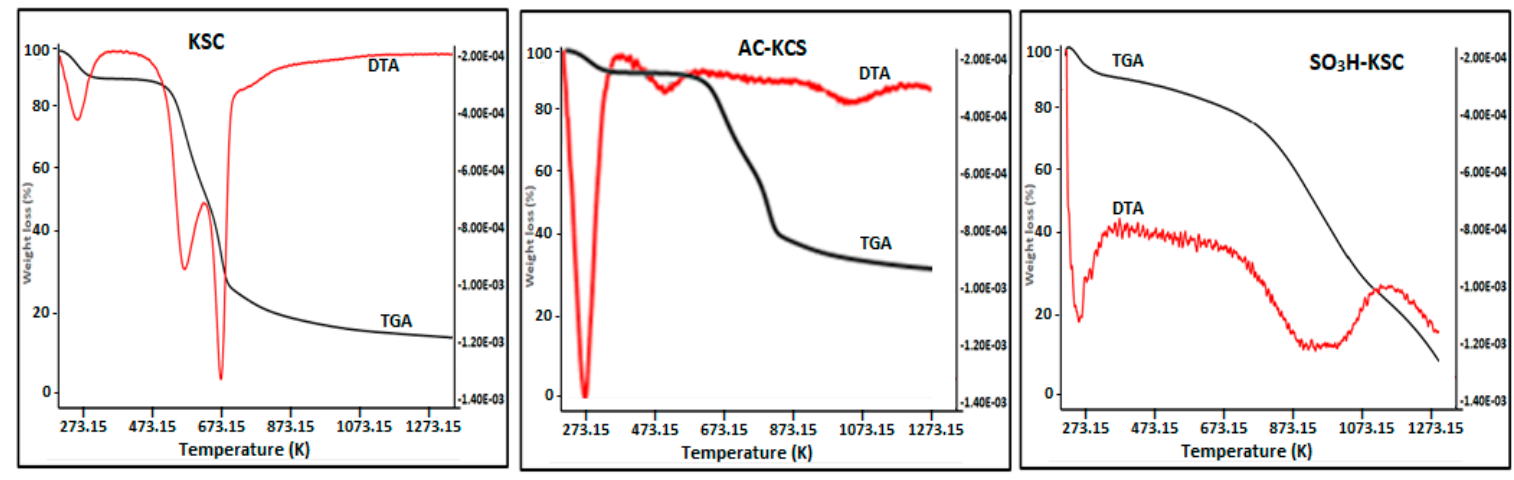

Figure 5. TGA illustration of $\mathrm{KSC}, \mathrm{AC}-\mathrm{KSC}$ and $\mathrm{SO}_{3} \mathrm{H}-\mathrm{KSC}$ catalysts.

The initial weight for the KSC, AC-KSC and $\mathrm{SO}_{3} \mathrm{H}-\mathrm{KSC}$ was $6.1 \mathrm{mg}$ and the first $\%$ weight loss was similar for all three materials. The $\mathrm{SO}_{3} \mathrm{H}-\mathrm{KSC}$ had about a $7.6 \%$ weight loss with a right limit at $296.21 \mathrm{~K}$ and a left limit at $399.95 \mathrm{~K}$. This means the catalyst lost about $7 \%(0.8 \mathrm{mg})$ of its weight, which is attributable to moisture content loss and other less volatile components, either as contaminants or components of biomass (cellulose). The next weight loss has a left limit value of $435 \mathrm{~K}$ and a right limit value of $594 \mathrm{~K}$ and a weight loss of $30 \%$ ( $3 \mathrm{mg}$ ). This loss is due to the hemicellulose component of the bio-based $\mathrm{SO}_{3} \mathrm{H}-\mathrm{KSC}$ and the $-\mathrm{SO}_{3} \mathrm{H}$ functional group. The last recorded weight loss has a left limit value of $594.15 \mathrm{~K}$ and a right limit value of $894.15 \mathrm{~K}$ while losing about $31 \%$ of its weight. This loss can be attributable to lignin, which is known to decompose at higher temperatures, $773.15 \mathrm{~K}$ and above, for KSC and AC-KSC. Therefore, the DTA and TGA have shown that our synthesized bio-based $\mathrm{SO}_{3} \mathrm{H}-\mathrm{KSC}$ catalyst has the thermal temperament to withstand the rigors of esterification, 
since our optimized temperature was $338.15 \mathrm{~K}$. The thermal strength and breakdown of bio-based catalysts reported elsewhere [22] is similar to what we have reported in this work.

\subsubsection{Surface Properties}

The pretreatment of the $\mathrm{SO}_{3} \mathrm{H}-\mathrm{KSC}$ with phosphoric acid was investigated with the BrunauerEmmett-Teller (BET) specific surface area analysis. The nitrogen desorption/adsorption isotherms are shown in Figure 6 below. As expected, the KSC had a low specific surface area and pore diameter, which is typical of a type I microporous material, whereas the AC-KSC and the $\mathrm{SO}_{3} \mathrm{H}-\mathrm{KSC}$ had features that are characteristic of type IV mesoporous materials. However, the $\mathrm{SO}_{3} \mathrm{H}-\mathrm{KSC}$ showed an enhanced pore diameter, improved specific surface area and larger pore sizes. Table 1 presents the pore volume $\left(0.02 \mathrm{~cm}^{3} / \mathrm{g}\right)$, pore diameter $(0.93 \mathrm{~nm})$ and specific surface area $\left(32.01 \mathrm{~m}^{2} / \mathrm{g}\right)$, of KSC, which are quite low when compared to those of AC-KSC and $\mathrm{SO}_{3} \mathrm{H}-\mathrm{KSC}$. The AC-KSC has a specific surface area of $375.18 \mathrm{~m}^{2} / \mathrm{g}$, pore volume of $0.39 \mathrm{~cm}^{3} / \mathrm{g}$ and a pore diameter of $3.07 \mathrm{~nm}$, while the $\mathrm{SO}_{3} \mathrm{H}-\mathrm{KSC}$ recorded a specific surface area of $365.63 \mathrm{~m}^{2} / \mathrm{g}$, pore volume of $0.31 \mathrm{~m}^{3} / \mathrm{g}$ and pore diameter of $2.89 \mathrm{~nm}$. These features are consistent with a type IV mesoporous bio-based material [28]. These findings will further highlight the vital role of phosphoric acid in the pretreatment of bio-based material for catalysts, as reported in previous works [21,29].

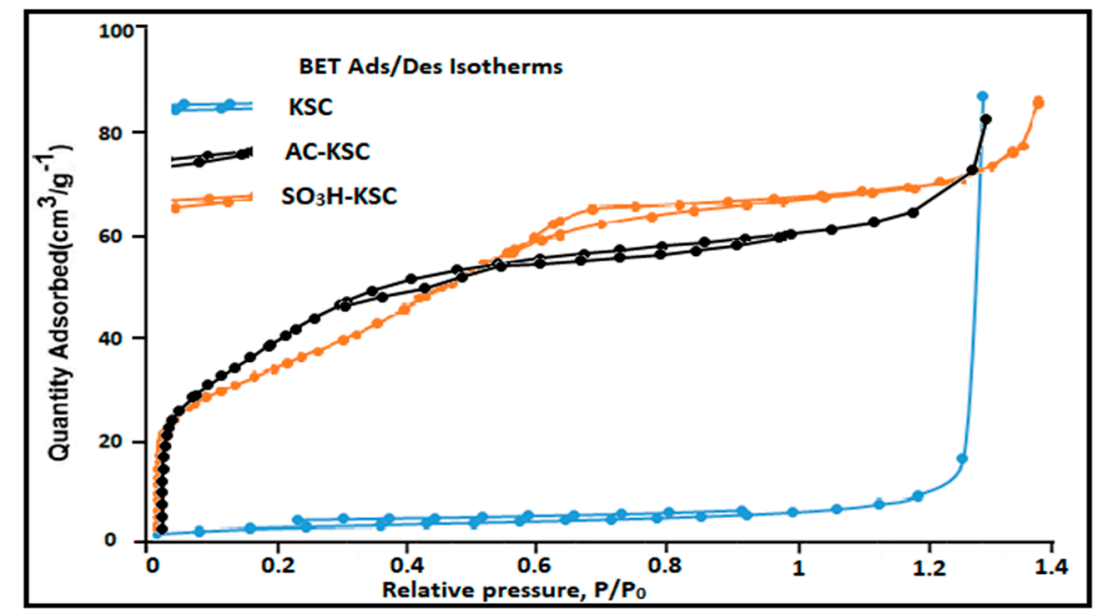

Figure 6. BET adsorption and desorption isotherms of $\mathrm{KSC}, \mathrm{AC}-\mathrm{KSC}$ and $\mathrm{SO}_{3} \mathrm{H}-\mathrm{KSC}$.

\subsection{Composition of PFAD and FAME}

Table 3 presents the composition of PFAD and FAME. Using the AOCS method Ca 5a-40, we determined the FFA ( $90 \mathrm{wt} . \%)$ and saponification $(210.15 \mathrm{mg} \mathrm{KOH} / \mathrm{g})$ values of the crude PFAD that served as our feedstock. Of the $90 \mathrm{wt}$. \% of FFA, palmitic acid $(49.23 \%)$ and oleic acid $(37.91 \%)$ were predominant, together comprising about $87.14 \%$, with linoleic acid $6.6 \%$, stearic acid $4.0 \%$ and myristic acid $0.9 \%$ making up the remainder. The PFAD also contained about $6 \%$ triglycerides (TG), $3 \%$ diglycerides (DG), $0.5 \%$ monoglycerides (MG) and a number of impurities. The FAME on the other hand contained methyl palmitate $(54.02 \%)$, methyl oleate $(33.40 \%)$, methyl stearate $(2.84 \%)$, methyl myristate $(1.44 \%)$ and others $(0.2 \%)$. 
Table 3. Characteristics of palm fatty acid distillate (PFAD) and fatty acid methyl esters (FAME).

\begin{tabular}{ccc}
\hline Properties & PFAD & Methods \\
\hline Saponification value & 210.15 & AOCS Cd-3-25 \\
Iodine value & 51.07 & AOCS Cd 1-25 \\
Free Fatty Acid content (\%) & 90 & AOCS Ca 5a-40 \\
Acid Value (mg KOH) (g sample) ${ }^{-1}$ & 180 & \\
Moisture content (\%) & 0.11 & AOCS Aa 3-38 \\
\hline Fatty acid composition (wt. $\%)$ & PFAD & FAME \\
\hline Palmitic acid, C16:0 & 49.23 & 54.02 \\
Oleic acid, C18:1 & 37.91 & 33.43 \\
Linoleic acid, C18:2 & 7.87 & 8.12 \\
Stearic acid, C18:0 & 3.75 & 2.84 \\
Myristic acid, C14:0 & 1.04 & 1.44 \\
Triglycerides & 6.00 & - \\
Diglycerides & 3.00 & - \\
Monoglycerides & 0.50 & - \\
Others & 0.2 & 0.15 \\
\hline
\end{tabular}

\subsection{Esterification Optimization Variables}

\subsubsection{Reaction Temperature}

Ass an important esterification process variable, temperature was studied in Kelvin units by varying the temperature from $323 \mathrm{~K}$ to $348 \mathrm{~K}$. While these temperatures were varied, the other variables (reaction time, 120 mins; catalyst amount, $2.5 \mathrm{wt} . \%$; molar ratio of methanol:PFAD, 9:1) were all kept constant. For protonation to occur, activation energy is required since we are dealing with an exothermic reaction [30]. As the temperature increases, so does the FFA conversion and FAME yield. At $333 \mathrm{~K}$, a 95\% FFA was converted and a FAME yield of $91 \%$ was recorded as seen in Figure 7a, which incidentally happened to be the highest FFA conversion and FAME yield recorded. When the temperature was increased to $343 \mathrm{~K}$ and $348 \mathrm{~K}$, there was no significant increase in either the FFA conversion or the FAME yield. Therefore, we adopted $333 \mathrm{~K}$ as our optimum reaction temperature for this study. FFA conversion is directly affected by temperature, when increased from $323.15 \mathrm{~K}$ to $333.15 \mathrm{~K}$, as highlighted in previous works [31,32]. In an attempt to optimize FAME yield, 98.28\% of FFA conversion was achieved when $353.15 \mathrm{~K}$ of reaction temperature was employed, as reported elsewhere [33].

\subsubsection{Reaction Time}

In a single-pot batch reflux system, the effect of reaction time on the FAME yield and FFA conversion was investigated and the results are presented in Figure $7 \mathrm{~b}$. A certain contact time is needed for the $\mathrm{SO}_{3} \mathrm{H}-\mathrm{KSC}$, methanol and the PFAD to have optimum FFA conversion and FAME yield. In the optimization process, we varied the reaction time from 30 to $180 \mathrm{~min}$ while keeping all other process variables constant, i.e., reaction temperature of $333.15 \mathrm{~K}, 2.5 \mathrm{wt} . \%$ of catalyst dosage and 10:1 molar ratio of methanol:PFAD. There was an obvious increment in the FFA conversion and FAME yield as the time increased; however, the highest FFA conversion was recorded at $90 \mathrm{~min}$, when $96 \%$ of FFA was converted and the FAME yield was $95 \%$. Although we continued the reaction runs until $180 \mathrm{~min}$, there was no further increment in either the FAME yield or the FFA conversion; thus, we chose $90 \mathrm{~min}$ as our optimum reaction time for this study. From the literature review, we have seen that our synthesized catalyst achieved a better reaction time than most of the work on bio-based materials. In a similar report where a biochar sulfonated catalyst was synthesized, it took $180 \mathrm{~min}$ to achieve $92 \%$ conversion with a similar catalyst concentration of $5 \mathrm{wt} . \%$ [34]. 


\subsubsection{Molar Ratio of Methanol: PFAD}

The quantity of methanol used is one of the most important variables in esterification reaction. To optimize the best quantity of methanol required to have the best possible FFA conversion and FAME yield, we took our reading from 2:1 to 14:1, as presented in Figure 7c. We took guidance from the literature review, in keeping some parameters constant while we ran all the samples. We maintained a temperature of $333.15 \mathrm{~K}$, a catalyst dosage of $2.5 \mathrm{wt} . \%$ and $120 \mathrm{mins}$ of reaction time. We deduced that as we increased the molar ratio concentration down the reaction line, the conversion and yield also increased. We recorded the highest FFA conversion (95\%) at a 10:1 methanol-to-PFAD molar ratio. However, we continued for another two runs at 12:1 and 14:1 to confirm whether the conversion could be improved on, but it reduced to and maintained 93\% for both the 12:1 and 14:1 methanol-PFAD molar ratios, respectively. During the esterification reaction it is expected that excess water may be produced, which will then react with our feedstock while there is a higher possibility of the reaction being pushed backwards. Furthermore, since esterification is a reversible reaction, there is a chance that when an excess dose of alcohol is applied during the reaction, it serves to push the reaction to the product side. However, we did not observe this principle in this case [26,29,30,35-38]. Therefore, we adopted 10:1 as our optimized reaction condition for the methanol-PFAD molar ratio. In previous studies, where the molar ratio of 15:1 methanol: oil was used, a 98.28\% fatty acid conversion was achieved [33], while another report recorded a molar ratio of 24:1 [39]. Thus, the results we have reported in this work have outperformed other scholarly works based on the concentration of methanol: PFAD used.

\subsubsection{Catalyst Concentration}

As presented in Figure $7 \mathrm{~d}$, we studied the effect of $\mathrm{SO}_{3} \mathrm{H}-\mathrm{KSC}$ catalyst usage. The catalyst dose ranged from 0.5 to $3 \mathrm{wt} . \%$. As expected, there was an evident increase in FFA conversion and FAME yield as the catalyst dosage increased. This trend continued until $2.5 \mathrm{wt} . \%$ where $92 \%$ conversion and 90\% FAME yield were recorded. This development showed a slight drop in the conversion and yield as compared to the $93 \%$ FFA conversion and $92 \%$ FAME yield recorded when 2 wt. $\% \mathrm{SO}_{3} \mathrm{H}-\mathrm{KSC}$ was administered. The last run for the stream records $91 \%$ FFA conversion and $89 \%$ FAME yield. While running for all these variables, we kept the time $(120 \mathrm{~min})$, catalyst loading ( $2.5 \mathrm{wt} . \%)$ and reaction temperature $(333 \mathrm{~K})$ constant.

Although, we need a good amount of catalyst to achieve maximum yield and conversion of methyl esters, in this case, there was no need to increase the catalyst dosage since it will not lead to an increase in yield and conversion of FFA, provided the equilibrium point has been reached [39]. Hence, our optimized weight for catalyst dose of $2 \mathrm{wt} . \%$. $120 \mathrm{mins}, 10: 1$ methanol: PFAD molar ratio, and $333.15 \mathrm{~K}$ reaction temperature were all kept constant during weight optimization of the catalyst. In a previous study [40], researchers utilized $7 \mathrm{wt} . \%$ of their bio-based solid acid catalyst to achieve $96 \%$ conversion of FFA.

\subsection{FAME Yield at Optimum Conditions}

In the present study, our derived optimum conditions (90 mins, $338.15 \mathrm{~K}, 10: 1$ and $2 \mathrm{wt.} \%$ ) achieved $97.9 \%$ and $98.7 \%$ yield and conversion of FFA, respectively. Methyl palmitate (54.02\%) had the highest methyl ester concentration followed by methyl oleate $(33.40 \%)$. Methyl stearate $(2.84 \%)$, methyl myristate $(1.44 \%)$ and methyl linoleate $(8.12 \%)$ were all recorded as part of the methyl esters. 


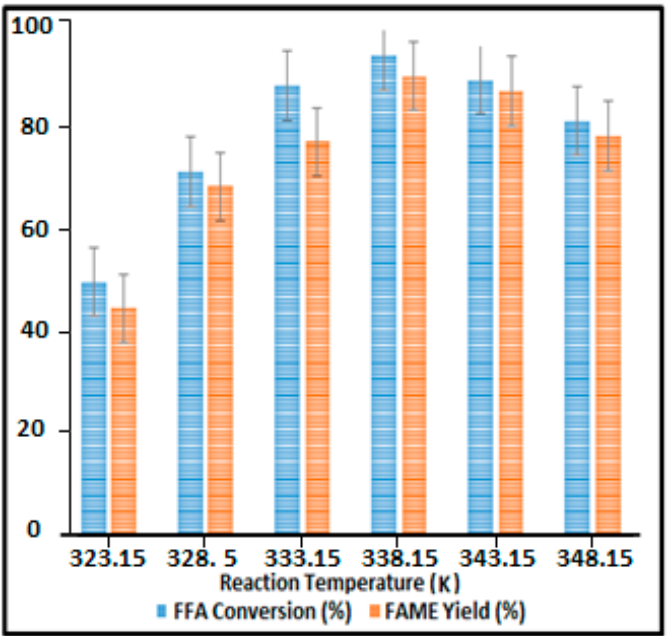

(a)

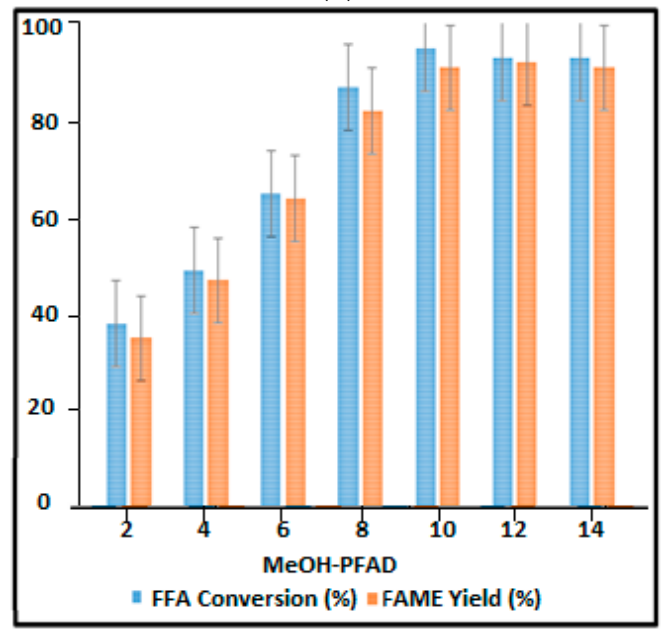

(c)

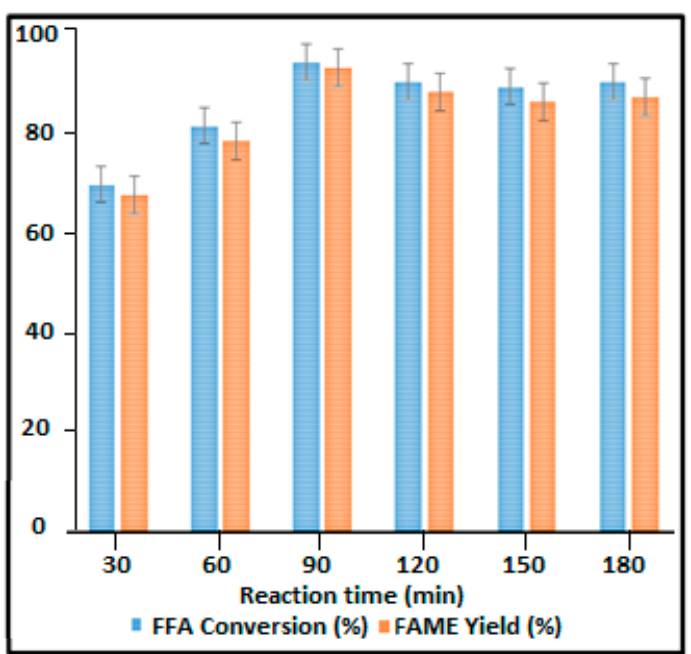

(b)

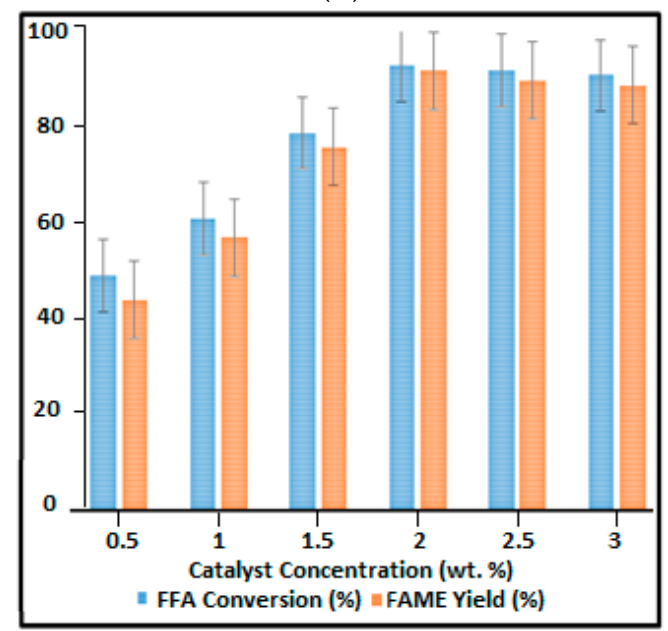

(d)

Figure 7. Reaction variables: (a) the reaction temperature; (b) reaction time; (c) methanol-PFAD molar ratio; and (d) catalyst concentration (wt.\%).

\section{6. $\mathrm{SO}_{3} \mathrm{H}-\mathrm{KSC}$ Reusability}

Bio-based heterogeneous solid acid catalysts have always had an advantage over homogeneous solid catalysts because of their reusability. This characteristic has distinguished them from liquid-based catalysts, and thus it is important to highlight this unique feature. The synthesized bio-based $\mathrm{SO}_{3} \mathrm{H}-\mathrm{KSC}$ catalyst underwent five reaction runs without reactivation, as presented in Figure 8.

Throughout these runs, it was stable and yielded $>90 \%$ FAME. After each run, the catalyst was washed and dried in an oven for $24 \mathrm{~h}$ and then prepared for the next run. Table 2 highlights the elemental and acid site density analysis of $\mathrm{KSC}$, AC-KSC and $\mathrm{SO}_{3} \mathrm{H}-\mathrm{KSC}$, where we recorded readings for sulfur, oxygen, phosphorus and carbon for the first runs. As reported elsewhere, five (5) reaction cycles were run using heterogeneous catalysts for the production of biodiesel [41], while other researchers have reported four reaction cycles [33]. It is also important to highlight the FT-IR spectra of the recovered-kenaf seed cake (R-KSC), as shown in Figure 9. The complete decomposition of the $-\mathrm{SO}_{3} \mathrm{H}$ functional group was observed as compared to the $\mathrm{SO}_{3} \mathrm{H}-\mathrm{KSC}$. This suggests that after the sixth reaction run, the $\mathrm{SO}_{3} \mathrm{H}-\mathrm{KSC}$ is deactivated and needs a further reactivation as the properties of the KSC are still intact and can support further reactivation. 


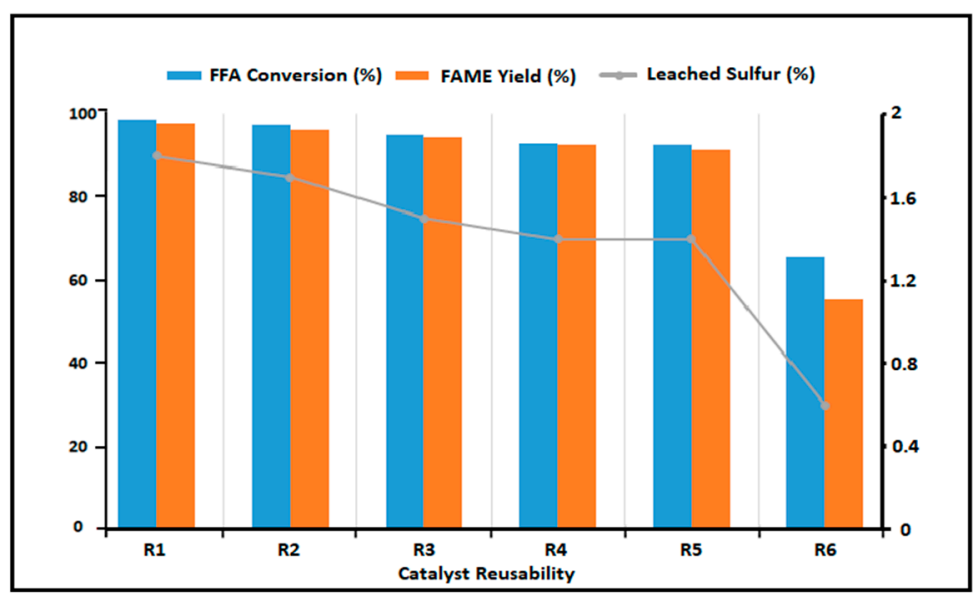

Figure 8. Reusability: FFA conversion (\%), FAME yield (\%) and leached ion sulfur (\%).

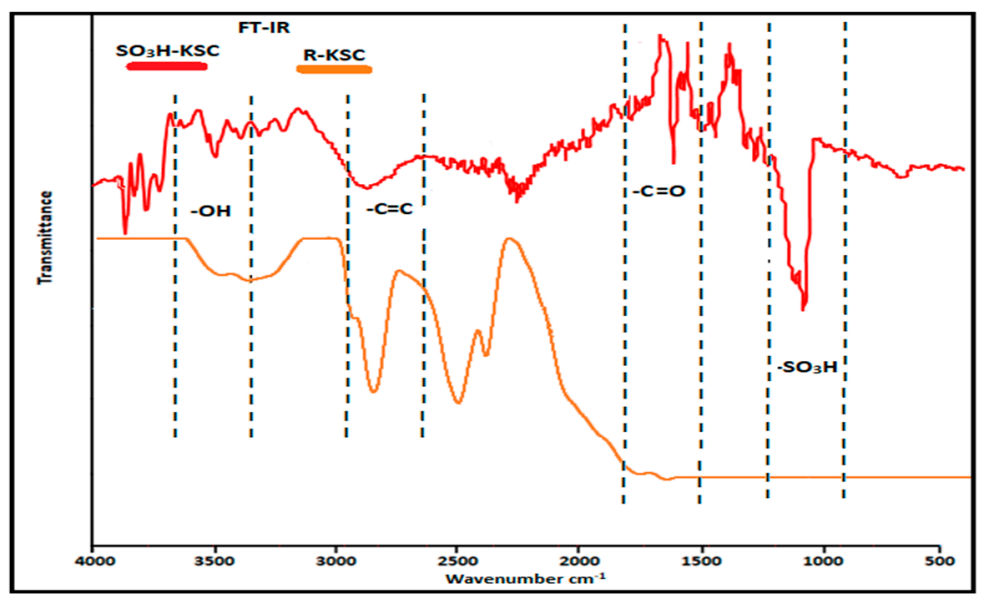

Figure 9. FT-IR spectra of $\mathrm{SO}_{3} \mathrm{H}-\mathrm{KSC}$ and recovered-kenaf seed cake (R-KSC) catalysts.

\section{Materials and Methods}

\subsection{Materials}

Kenaf (Hibiscus cannabinus, L), was collected from National Kenaf and Tobacco, Kelantan, Malaysia, while PFAD was sourced from Sime Darby Group Sdn. Bhd., Malaysia. The feedstock, PFAD, comprised $90 \mathrm{wt} . \%$ of FFA (linoleic acid $6.6 \%$, oleic acid $33.2 \%$, stearic acid $4.0 \%$, myristic acid $0.9 \%$ and palmitic acid $45.3 \%$ ). It also contained about $6 \%$ triglycerides (TG), $3 \%$ diglycerides (DG), $0.5 \%$ monoglycerides (MG) and some traces of impurities. Methyl palmitate, methyl linoleate, methyl oleate, methyl heptadecanoate, methyl myristate and methyl stearate were almost 100\% analytical grade standard obtained from J. T. Baker and used for the FAME yield determination using gas chromatography (GC-FID). n-hexane (90\%), methanol (99\%), propanol (99\%) and ethyl alcohol (99\%) were all obtained from Sigma-Aldrich. Concentrated $\mathrm{H}_{2} \mathrm{SO}_{4}(98 \%)$ and $\mathrm{KOH}(86 \%)$ were obtained from Fisher Scientific International Inc. Phenolphthalein and $\mathrm{H}_{3} \mathrm{PO}_{4}(50 \%)$ were purchased from Merck \& $\mathrm{Co}$, pharmaceutical company, USA. The iodine, FFA and saponification values of the crude PFAD were measured with standard methods.

\subsection{Catalyst Synthesis}

The first step in the synthesis of the catalyst was to subject it to chemical activation. This process is crucial because it helps improve the pore volume and the specific surface area of bio-based catalysts [34]. Two streams of kenaf seed cake bio-based materials were prepared and subjected to pretreatment. The first sample (KSC) was subjected to heating via pyrolysis under a flow of $\mathrm{N}_{2}$, without pretreatment 
with phosphoric acid, while the second sample of powdered kenaf seed cake was soaked in $\mathrm{H}_{3} \mathrm{PO}_{4}$ to achieve chemical activation. A 2:1 (w/w) impregnation ratio was used for $24 \mathrm{~h}$ at room temperature to facilitate high porosity and specific surface area development [42]. Thereafter, $\mathrm{H}_{3} \mathrm{PO}_{4}-\mathrm{KSC}$ was calcined by measuring the desired quantity into a glass boat and placing in a crucible tube furnace for $2 \mathrm{~h}$ under a flow of $\mathrm{N}_{2}$ at $673.15 \mathrm{~K}$.

The sulfonation process was next, after the calcination, and $10 \mathrm{~g}$ of $\mathrm{H}_{3} \mathrm{PO}_{4}-\mathrm{KSC}$ was sulfonated with $250 \mathrm{~mL}$ of concentrated $\mathrm{H}_{2} \mathrm{SO}_{4}$ at $423.15 \mathrm{~K}$ under a $\mathrm{N}_{2}$ flow for $12 \mathrm{~h}$ in a reflux reactor. The synthesized $\mathrm{H}_{3} \mathrm{PO}_{4}-\mathrm{KSC}$ was allowed to reach room temperature before washing with ionized distilled $\mathrm{H}_{2} \mathrm{O}$, and thereafter the synthesized catalyst was kept in an oven for $12 \mathrm{~h}$ at $353.15 \mathrm{~K}$ to remove excess moisture.

\subsection{Catalyst Characterization}

The sulfonated kenaf seed cake catalyst $\left(\mathrm{SO}_{3} \mathrm{H}-\mathrm{KSC}\right)$ characterization was thorough, with six different material characterization analyses. A FESEM (FEI, NOVA NANOSEM 230, Thermo Fisher Scientific Inc., Oregon, USA) machine was used for the surface morphology of the $\mathrm{SO}_{3} \mathrm{H}-\mathrm{KSC}$, via a high magnifying FESEM. A Mettler Toledo 990 machine (Mettler-Toledo (M) Sdn Bhd, Shah Alam Selangor, Malaysia) was used to investigate the thermal stability of our synthesized catalyst via thermogravimetric analysis (TGA) and differential thermogravimetry (DTG). Confirmation of the successful attachment of the $-\mathrm{SO}_{3} \mathrm{H}$ functional group on the KSC catalyst, was achieved with the Nicolet 6700 equipment (Thermo Nicolet, Thermo Fisher Scientific Inc., Oregon, USA) for the Fourier transform infrared (FTIR) analysis. A Shimadzu, X-ray diffraction (XRD)-6000 machine (Shimadzu Corporation, Tokyo, Japan) was used to check the KSC crystallite size and structure via powdered XRD, with a scanning range and rate of theta $(\theta)$ from 20 to 80 and $4 \mathrm{~min}^{-1}$ respectively. We used Scherrer's formula $(\mathrm{D}=\mathrm{K} \lambda / \beta \cos \theta)$ to estimate the crystallinity of the $\mathrm{SO}_{3} \mathrm{H}-\mathrm{KSC}$. The Thermo Finnigan, TPDRO 1100 series was used for the analysis of the active acid site distribution and acid density, via the ammonia-temperature programmed desorption $\left(\mathrm{NH}_{3}-\mathrm{TPD}\right)$ and the carrier gas used was helium. Samples were degassed at $423 \mathrm{~K}$ with nitrogen and heated for $12 \mathrm{~h}$, in order to prepare the samples for the surface area analyses. The Thermo Finnigan instrument (Sorptomatic 1990 series) (Thermo Fisher Scientific Inc., Oregon, USA). was used for the specific surface area analysis and the calculation was achieved using the Brunauer-Emmett-Teller (BET) method. The pore size distribution calculation was achieved by employing the Barrette-Joyner-Halenda (BJH) approach and mesopore mean diameter by using data obtained from the desorption of the isotherms.

\subsection{Experimental Setup for Esterification}

The effects of different esterification reaction variables of the synthesized $\mathrm{SO}_{3} \mathrm{H}-\mathrm{KSC}$ were analyzed. Molar ratios of MeOH/PFAD ranged from 2:1 to 14:1, the $\mathrm{SO}_{3} \mathrm{H}-\mathrm{KSC}$ amount from 0.5 to 3.0 (wt.\%), the reaction temperature from $323 \mathrm{~K}$ to $348 \mathrm{~K}$, and the reaction time from 30 to $180 \mathrm{mins}$. In a typical esterification reaction, the weight of PFAD, the volume of methanol, the molecular weight of the PFAD and catalysts weight percentage were all measured in calculated proportions and mixed in a $500 \mathrm{~mL}$ 2-necked round bottom flask in a conventional reflux system. A condenser was plugged into the top of the 2-necked flask which helped to maintain a good balance of the total amount of methanol in the reflux reactor. The esterification reaction was set in a reflux reactor which was placed in a silicon oil water bath. The molar ratio of the methanol-PFAD, catalyst concentration, reaction temperature and time were all varied during the esterification reaction. In a typical esterification reaction setup, for a $2.5 \mathrm{wt}$.\% of catalyst amount, catalyst $(0.5 \mathrm{~g})$, PFAD (20 g) and methanol (21.35 g) were all placed alongside a stirrer in a flask reactor, with $550 \mathrm{rpm}$ stirring speed. Depending on the volume, the content of the reflux reactor was emptied into a centrifuge plastic bottle and set to spin at $7000 \mathrm{rpm}$ for about 30 mins. This was done so that the separation process would be easier and quicker. Based on the volume of the mixture, measured methanol was further used to wash the synthesized catalyst which was then dried for a few hours in an oven set at $273.15 \mathrm{~K}$, after which it was removed and kept for 
further reuse tests. After separation, the FAME was placed on a hot plate set at $338.15 \mathrm{~K}$ for $60 \mathrm{~min}$ to purge any remnant methanol.

\subsection{FAME Analysis}

The yield and conversion of the FAME were calculated according to established standards (AOCS Ca 5a-40), as shown in Equation (1) below. These calculations basically show the differences between the acid values of the feedstock and the product [43]. Where FFA value of feedstock and FFA value of product stand for the PFAD acid value and the FAME value of the FFA produced, respectively.

$$
\text { Conversion }(\mathrm{FFA})[\%]=\frac{\text { FFA value of feedstock }- \text { FFA value of product }}{\text { FFA value of feedstock }} \times 100
$$

In analyzing the yield of the FAME, the EN 14103 method [44] was employed while using an Agilent GC capillary column $(0.32 \mathrm{~mm} \times 30 \mathrm{~m}, 0.25 \mu \mathrm{m})$. The temperature of the detector was set at $523.15 \mathrm{~K}$, the injection volume was $1 \mu \mathrm{L}$ and the oven was set at $483.15 \mathrm{~K}$. The method employed here requires several internal standards to be prepared (palmitic, oleic, stearic, linolenic, lauric, linoleic and myristic esters) and methyl heptadecanoic acid was prepared as the reference standard [44]. All reference standards-i.e., methyl oleate, methyl palmitate, methyl linoleate, methyl myristate and methyl stearate-were diluted to $1000 \mathrm{ppm}$ [13]. On average, we injected $1 \mu \mathrm{L}$ of the sample into the injector pot of the GC while the inlet temperature was set at $523.15 \mathrm{~K}$ and the FID was set at $543.15 \mathrm{~K}$. The GC oven's starting temperature was programmed to start at $273.15 \mathrm{~K}$ and increase to $523.15 \mathrm{~K}$ with the temperature rate set at $283.15 \mathrm{~K}$ min-1. The illustration in Equation (2) shows how we calculated the FAME yield:

$$
\mathrm{Y}=\frac{(\Sigma \mathrm{A})-\mathrm{AEI}}{\mathrm{AEI}} \times \frac{\mathrm{CEI} \times \mathrm{VEI}}{m} \times 100
$$

where: $\mathrm{Y}=$ FAME yield $(\%) ; \Sigma \mathrm{A}=$ total peak area of the FAME $\left(\mathrm{C}_{14: 0}\right.$ to $\left.\mathrm{C}_{24: 1}\right)$; $\mathrm{AEI}=$ peak area of methyl-heptadecanoate $(\%)$; CEI = concentration of methyl-heptadecanoate solution $(\mathrm{mg} / \mathrm{L})$; $\mathrm{VEI}=$ volume of methyl-heptadecanoate solution $(\mathrm{mL}) ;$ and, $\mathrm{m}=$ mass of the sample $(\mathrm{mg})$

\subsection{Catalyst Reusability Analysis}

The economical nature of sulfonated bio-based catalysts is emphasized by their ability to run several reaction cycles while remaining stable. After each esterification reaction we collected $0.2 \mathrm{~g}$ of $\mathrm{SO}_{3} \mathrm{H}-\mathrm{KSC}$ for the reusability test where we checked for the leached sulfur with the CHNS analysis using the LECO CHNS-932 spectrometer. After the FAME separation and water residue following each run, we washed the $\mathrm{SO}_{3} \mathrm{H}-\mathrm{KSC}$ catalyst with ethanol and hexane in a 2-step washing procedure, then dried it in the oven $(10 \mathrm{~h}$ at $353.15 \mathrm{~K})$ for recovery. These washing steps are necessary in order to remove all contaminants (polar/non-polar compounds) during and after the reaction phase. These reaction parameters: $2 \mathrm{wt} . \%$ of the $\mathrm{SO}_{3} \mathrm{H}-\mathrm{KSC}, 338.15 \mathrm{~K}$ of reaction temperature and $90 \mathrm{mins}$ for reaction time, and a molar ratio of 10:1 methanol: PFAD were used for the reusability study of the $\mathrm{SO}_{3} \mathrm{H}-\mathrm{KSC}$ catalyst. We maintained this process for each reaction run. We ran all samples in this work in triplicate sets, reported as the mean \pm standard deviation for the statistical analysis.

\section{Conclusions}

We have successfully demonstrated the sulfonation of bio-based kenaf seed cake to esterify a highly acidic PFAD in this study. We demonstrated that phosphoric acid greatly enhances the catalytic activity of bio-based materials as catalysts for FAME production. The sulfonated kenaf seed cake showed improved porosity, enhanced specific surface area, good acid distribution and thermal stability, and even better FAME yield and FFA conversion. At optimized reaction conditions of reaction time of $90 \mathrm{~min}$, reaction temperature of $338 \mathrm{~K}$, catalyst concentration of $2 \mathrm{wt} . \%$ and methanol-PFAD molar ratio of 10:1, we obtained extremely positive results of $98.7 \%$ FFA conversion and $97.9 \%$ FAME yield. We reused our synthesized catalyst for five reaction runs while maintaining FFA conversion and 
FAME yield above $90 \%$, because the leached sulfur content, as observed with the CHNS analysis, was insignificant. We have extensively shown, from the bio-based material characterization to the PFAD and FAME properties, that bio-based materials should be utilized more often either as a precursor for catalysts or as feedstock for the esterification of fats and oils.

Author Contributions: Conceptualization, S.-I.A. and U.R.; Experimental work and methodology, S.-I.A.; Writing-original draft, S.-I.A.; Help with editing, supervision and review of the manuscript, U.R.; Scientific guidance for successful completion of the project and help to review the final draft of the manuscript, T.Y.C.S.; Help to investigate the catalysts, I.A.N. and H.M.S.; and, in the final draft of the paper, assistance in the analysis of the biodiesel and raw material, M.M.G.

Funding: The authors acknowledge their gratitude to the Universiti Putra Malaysia via the Putra IPB grant for financial assistance through research grant number GP- IPB/2016/9490400. The authors also express their sincerest appreciation for the funding of this research by the Deanship of Scientific Research at the King Saud University through Research Group Project number RGP-048.

Conflicts of Interest: The authors declare no conflicts of interest.

\section{References}

1. Soltani, S.; Rashid, U.; Yunus, R.; Taufiq-Yap, Y.H. Biodiesel production in the presence of sulfonated mesoporous $\mathrm{ZnAl}_{2} \mathrm{O}_{4}$ catalyst via esterification of palm fatty acid distillate (PFAD). Fuel 2016, 178, $253-262$. [CrossRef]

2. Shuit, S.H.; Yee, K.F.; Lee, K.T.; Subhash, B.; Tan, S.H. Evolution towards the utilisation of functionalised carbon nanotubes as a new generation catalyst support in biodiesel production: An overview. RSC Adv. 2013, 3, 9070-9094. [CrossRef]

3. Demirbas, A. Biodiesel production via non-catalytic SCF method and biodiesel fuel characteristics. Energy Convers. Manag. 2006, 47, 2271-2282. [CrossRef]

4. Lee, A.F.; Bennett, J.A.; Manayil, J.C.; Wilson, K. Heterogeneous catalysis for sustainable biodiesel production via esterification and transesterification. Chem. Soc. Rev. 2014, 43, 7887. [CrossRef] [PubMed]

5. Sunita, G.; Devassy, B.M.; Vinu, A.; Sawant, D.P.; Balasubramanian, V.V.; Halligudi, S.B. Synthesis of biodiesel over zirconia-supported isopoly and heteropoly tungstate catalysts. Catal. Commun. 2008, 9, 696-702. [CrossRef]

6. Gupta, A.R.; Rathod, V.K. Waste cooking oil and waste chicken eggshells derived solid base catalyst for the biodiesel production: Optimization and kinetics. Waste Manag. 2018, 79, 169-178. [CrossRef]

7. Peng-Lim, B.; Ganesan, S.; Maniam, G.P.; Khairuddean, M. Sequential conversion of high free fatty acid oils into biodiesel using a new catalyst system. Energy 2012, 46, 132-139. [CrossRef]

8. Carlucci, C.; Degennaro, L.; Luisi, R. Titanium dioxide as a catalyst in biodiesel production. Catalysts 2019, 9, 75. [CrossRef]

9. Yang, B.; Leclercq, L.; Clacens, J.M.; Nardello-Rataj, V. Acidic/amphiphilic silica nanoparticles: New eco-friendly pickering interfacial catalysis for biodiesel production. Green Chem. 2017, 19, 4552-4562. [CrossRef]

10. Thanh, L.T.; Okitsu, K.; Van Boi, L.; Maeda, Y. Catalytic technologies for biodiesel fuel production and utilization of glycerol: A review. Catalysts 2012, 2, 191-222. [CrossRef]

11. Tahery, Y.; Shukor, N.A.A.; Abdul-Hamid, H. Growth characteristics and biomass production of kenaf. Afr. J. Biotechnol. 2011, 10, 13756-13761. [CrossRef]

12. Khalil, H.A.; Yusra, A.I.; Bhat, A.H.; Jawaid, M. Cell wall ultrastructure, anatomy, lignin distribution, and chemical composition of Malaysian cultivated kenaf fiber. Ind. Crops Prod. 2010, 31, 113-121. [CrossRef]

13. Akinfalabi, S.I.; Rashid, U.; Yunus, R.; Taufiq-Yap, Y.H. Synthesis of biodiesel from palm fatty acid distillate using sulfonated palm seed cake catalyst. Renew. Energy 2017, 111, 611-619. [CrossRef]

14. Chin, L.H.; Abdullah, A.Z.; Hameed, B.H. Sugar cane bagasse as solid catalyst for synthesis of methyl esters from palm fatty acid distillate. Chem. Eng. J. 2012, 183, 104-107. [CrossRef]

15. Li, M.; Zheng, Y.; Chen, Y.; Zhu, X. Biodiesel production from waste cooking oil using a heterogeneous catalyst from pyrolyzed rice husk. Bioresour. Technol. 2014, 154, 345-348. [CrossRef] 
16. Mundi, I. Malaysia Palm Oil Production by Year. 2017. Available online: http://bepi.mpob.gov.my/index. php/en/statistics/production/177-production-2017/792-production-of-crude-oil-palm-2017.html (accessed on 3 March 2019).

17. Chongkhong, S.; Tongurai, C.; Chetpattananondh, P.; Bunyakan, C. Biodiesel production by esterification of palm fatty acid distillate. Biomass Bioenergy 2007, 31, 563-568. [CrossRef]

18. Roschat, W.; Siritanon, T.; Yoosuk, B.; Promarak, V. Rice husk-derived sodium silicate as a highly efficient and low-cost basic heterogeneous catalyst for biodiesel production. Energy Convers. Manag. 2016, 119, 453-462. [CrossRef]

19. Shehu-Ibrahim, A.; Rashid, U.; Yunus, R.; Taufiq-Yap, Y.H. Appraisal of sulphonation processes to synthesize palm waste biochar catalysts for the esterification of palm fatty acid distillate. Catalysts 2019, 9, 184. [CrossRef]

20. Omri, A.; Benzina, M. Characterization of activated carbon prepared from a new raw lignocellulosic material: Ziziphus spina-christi seeds. J. Soc. Chim. Tunis. 2012, 14, 175-183.

21. Shamsuddin, M.S.; Yusoff, N.R.N.; Sulaiman, M.A. Synthesis and characterization of activated carbon produced from kenaf core fiber using $\mathrm{H}_{3} \mathrm{PO}_{4}$ activation. Procedia Chem. 2016, 19, 558-565. [CrossRef]

22. Al-Jaberi, S.H.H.; Rashid, U.; Fairs, A.-D.; Abdulkareem-Alsultan, G.; Taufiq-Yap, Y.H. Synthesis of $\mathrm{MnO}-\mathrm{NiO}-\mathrm{SO}_{4}{ }^{-2} / \mathrm{ZrO}_{2}$ solid acid catalyst for methyl ester production from palm fatty acid distillate. Energy Convers. Manag. 2017, 139, 166-174. [CrossRef]

23. Lokman, M.I.; Rashid, U.; Taufiq-Yap, Y.H.; Yunus, R. Methyl ester production from palm fatty acid distillate using sulfonated glucose-derived acid catalyst. Renew. Energy 2015, 81, 347-354. [CrossRef]

24. Kastner, J.R.; Miller, J.; Geller, D.P.; Locklin, J.; Keith, L.H.; Johnson, T. Catalytic esterification of fatty acids using solid acid catalysts generated from biochar and activated carbon. Catal. Today 2012, 190, 122-132. [CrossRef]

25. Dawodu, F.A.; Ayodele, O.; Xin, J.; Zhang, S.; Yan, D. Effective conversion of non-edible oil with high free fatty acid into biodiesel by sulphonated carbon catalyst. Appl. Energy 2014, 114, 819-826. [CrossRef]

26. Okamura, M.; Takagaki, A.; Toda, M.; Kondo, J.N.; Domen, K.; Tatsumi, T.; Hara, M.; Hayashi, S. Acid-catalyzed reactions on flexible polycyclic aromatic carbon in amorphous carbon. Chem. Mater. 2006, 18, 3039-3045. [CrossRef]

27. Ezebor, F.; Khairuddean, M.; Abdullah, A.Z.; Boey, P.L. Esterification of oily-FFA and transesterification of high FFA waste oils using novel palm trunk and bagasse-derived catalysts. Energy Convers. Manag. 2014, 88, 1143-1150. [CrossRef]

28. Fadhil, A.B.; Aziz, A.M.; Al-Tamer, M.H. Biodiesel production from Silybum marianum L. seed oil with high FFA content using sulfonated carbon catalyst for esterification and base catalyst for transesterification. Energy Convers. Manag. 2016, 108, 255-265. [CrossRef]

29. Tran, T.T.V.; Kaiprommarat, S.; Kongparakul, S.; Reubroycharoen, P.; Guan, G.; Nguyen, M.H.; Samart, C. Green biodiesel production from waste cooking oil using an environmentally benign acid catalyst. Waste Manag. 2016, 52, 367-374. [CrossRef] [PubMed]

30. Liu, T.; Li, Z.; Li, W.; Shi, C.; Wang, Y. Preparation and characterization of biomass carbon-based solid acid catalyst for the esterification of oleic acid with methanol. Bioresour. Technol. 2013, 133, 618-621. [CrossRef]

31. Leung, D.Y.C.; Guo, Y. Transesterification of neat and used frying oil: Optimization for biodiesel production. Fuel Process. Technol. 2006, 87, 883-890. [CrossRef]

32. Hayyan, A.; Alam, M.Z.; Mirghani, M.E.; Kabbashi, N.A.; Hakimi, N.I.N.M.; Siran, Y.M.; Tahiruddin, S. Reduction of high content of free fatty acid in sludge palm oil via acid catalyst for biodiesel production. Fuel Process. Technol. 2011, 92, 920-924. [CrossRef]

33. Guldhe, A.; Moura, C.V.; Singh, P.; Rawat, I.; Moura, E.M.; Sharma, Y.; Bux, F. Conversion of microalgal lipids to biodiesel using chromium-aluminum mixed oxide as a heterogeneous solid acid catalyst. Renew. Energy 2017, 105, 175-182. [CrossRef]

34. Dehkhoda, A.M.; West, A.H.; Ellis, N. Biochar based solid acid catalyst for biodiesel production. Appl. Catal. A Gen. 2010, 382, 197-204. [CrossRef]

35. Vernersson, T.; Bonelli, P.R.; Cerrella, E.G.; Cukierman, A.L. Arundo donax cane as a precursor for activated carbons preparation by phosphoric acid activation. Bioresour. Technol. 2002, 83, 95-104. [CrossRef]

36. Cimino, S.; Lisi, L.; De Rossi, S.; Faticanti, M.; Porta, P. Methane combustion and CO oxidation on LaAl1-xMnxO 3 perovskite-type oxide solid solutions. Appl. Catal. B Environ. 2003, 43, 397-406. [CrossRef] 
37. Konwar, L.J.; Das, R.; Thakur, A.J.; Salminen, E.; Mäki-Arvela, P.; Kumar, N.; Deka, D. Biodiesel production from acid oils using sulfonated carbon catalyst derived from oil-cake waste. J. Mol. Catal. A Chem. 2014, 388, 167-176. [CrossRef]

38. Zhang, J.; Jiang, L. Acid-catalyzed esterification of Zanthoxylum bungeanum seed oil with high free fatty acids for biodiesel production. Bioresour. Technol. 2008, 99, 8995-8998. [CrossRef] [PubMed]

39. Yujaroen, D.; Goto, M.; Sasaki, M.; Shotipruk, A. Esterification of palm fatty acid distillate (PFAD) in supercritical methanol: Effect of hydrolysis on reaction reactivity. Fuel 2009, 88, 2011-2016. [CrossRef]

40. Guo, F.; Xiu, Z.L.; Liang, Z.X. Synthesis of biodiesel from acidified soybean soapstock using a lignin-derived carbonaceous catalyst. Appl. Energy 2012, 98, 47-52. [CrossRef]

41. Alhassan, F.H.; Yunus, R.; Rashid, U.; Sirat, K.; Islam, A.; Lee, H.V.; Taufiq-Yap, Y.H. Production of biodiesel from mixed waste vegetable oils using Ferric hydrogen sulphate as an effective reusable heterogeneous solid acid catalyst. Appl. Catal. A Gen. 2013, 456, 182-187. [CrossRef]

42. Nahil, M.A.; Williams, P.T. Pore characteristics of activated carbons from the phosphoric acid chemical activation of cotton stalks. Biomass Bioenergy 2012, 37, 142-149. [CrossRef]

43. Malaysian Palm Oil Board (MPOB). 2016. Available online: www.mpob.gov.my (accessed on 3 March 2019).

44. Duvekot, C. Determination of Total FAME and Linoleic Acid Methyl Ester in Biodiesel According to EN-14103; Agilent Technologies: Santa Clara, CA, USA, 2011.

(C) 2019 by the authors. Licensee MDPI, Basel, Switzerland. This article is an open access article distributed under the terms and conditions of the Creative Commons Attribution (CC BY) license (http://creativecommons.org/licenses/by/4.0/). 